\title{
El socavamiento de los derechos humanos en la globalización actual: La crisis de poder de las burocracias privadas
}

Franz J. Hinkelammert

Hablamos de una crisis de poder de las burocracias privadas. Esto no significa que el poder ya está por derrumbarse. Las burocracias privadas siguen estando en el poder. Pero su poder está llegando a un punto crítico, que se hace presente como una encrucijada.

Para ver esto, analizamos las transnacionales como burocracias privadas. Hoy son grandes aparatos burocráticos que, tanto en su tamaño como en sus procedimientos, constituyen una burocracia privada, en función de la cual las burocracias públicas se están transformando en sus apéndices.

La gran empresa se transformó en burocracia privada desde los años 70 del siglo XIX. Ya en Max Weber encontramos este análisis de la gran empresa como burocracia privada. Sin embargo, después de la II Guerra Mundial, está empresa, que, desde sus comienzos, ha sido una empresa de carácter mundial, se transforma profundamente. Es ahora una empresa de producción mundial que, como burocracia privada, logra ponerse por encima de la burocracia pública y que hoy es el poder clave a partir del cual tenemos que tratar de comprender la situación del mundo y, específicamente, de América Latina. 
el poder clave a partir del cual tenemos que tratar de comprender la situación del mundo y, específicamente, de América Latina.

\section{La empresa de producción mundial}

La empresa de producción mundial es de un tipo nuevo. Aparece después de la II Guerra Mundial, pero su actividad se intensifica a partir de los años 70 del siglo XX.

No es la primera empresa mundial. Pero las empresas mundiales anteriores son de compra y venta mundial, mientras su producción está concentrada en determinados lugares del espacio terrestre. Los principales elementos del proceso de producción son producidos en un espacio restringido. Por eso, se puede hablar del made in England, made in Germany.

La empresa de producción mundial surge a partir de determinados inventos que la hacen posible:

1. Transmisión barata de mensajes con velocidad instantánea hacia todos los lugares de la Tierra. La transmisión instantánea de mensajes empieza a mediados del siglo XIX con la transmisión cablegráfica. Sin embargo, una transmisión instantánea hacia todos los lugares de la Tierra, que incluye imágenes en los mensajes, aparece recién después de la II Guerra Mundial.

2. Cálculos baratos con velocidad casi instantánea y con capacidad tendencialmente ilimitada. Estos cálculos aparecen también después de la II Guerra Mundial, especialmente a partir de los años 70.

3. Transportes mundiales baratos, que alcanzan cualquier lugar del mundo desde cualquier punto en menos de 24 horas. El mundo está al alcance del transporte, tanto de bienes como de personas.

Dadas estas condiciones, puede aparecer la empresa de producción mundial. Esta empresa puede distribuir las etapas de producción en el mundo entero $y$, a pesar de eso, funcionar tan coordinadamente como lo hacía con anterioridad una empresa, que unía estas etapas de producción en un solo espacio parcial. La empresa de producción mundial es una empresa cuyo proceso de producción se desenvuelve en una red mundial de división del trabajo referente a las etapas intermedias. Cada etapa puede estar en un lugar diferente según los costos de producción de los diferentes lugares posibles. Por eso, son sumamen- 
te móviles. La etapa final del proceso de producción se asemeja muchas veces a un simple lugar de ensamblaje.

A partir de los años 60 , estas empresas de producción mundial se desarrollan muy rápidamente. Son las empresas transnacionales, como se les llama muchas veces. Pero no solamente las grandes empresas conocidas desarrollan este carácter. También lo hacen muchas empresas de tamaño medio.

Ya mencionamos las condiciones que hacían posible la constitución de empresas de producción mundial: mensajes y cálculos instantáneos, transportes rápidos de alcance universal. Sin embargo, una vez posibles las empresas de producción mundial, aparecen otras condiciones de carácter institucional. Son condiciones que facilitan las posibilidades de estas empresas de lograr un rendimiento máximo. Las empresas ahora promueven nuevas condiciones institucionales para su funcionamiento, y presionan para que obtenerlas.

Se trata de condiciones institucionales de fluidez de los mercados, cuyo cumplimiento exige la empresa de producción mundial. Implican un cambio radical en relación con el capitalismo anterior. Este capitalismo era intervencionista y podía existir con políticas de intervención den los mercados de parte de los Estados nacionales. Sin embargo, la lógica de la empresa de producción mundial se opone radicalmente al anterior intervencionismo de la política económica de los Estados nacionales: a la protección de mercados, a la política de pleno empleo, a la planificación del desarrollo local, nacional y regional, al control de los flujos del capital y de las divisas, a las reservas del mercado impuestas por el Estado, a la propiedad pública, a políticas laborales en favor de la estabilidad laboral, a los sindicatos, etc.

Si queremos formular el conjunto de estas exigencias, que surgen desde el interior del funcionamiento de las empresas de producción mundial, lo encontramos en los ajustes estructurales, como fueron impuestos al mundo desde los años 80 . Son la otra cara de este funcionamiento, cuando se orienta por la maximización de su rendimiento. La promoción de las empresas de producción mundial y los ajustes estructurales son dos caras de una medalla. Aparecen con la empresa de producción mundial y los programas de ajuste estructural le dan sistematicidad y un nombre. 


\section{La estrategia resultante de la toma del poder por las burocracias privadas: los ajustes estructurales}

Los ajustes estructurales se refieren especialmente a tres dimensiones de la sociedad:

a) La apertura tendencialmente ilimitada para el capital financiero y las corrientes de divisas y mercancias.

b) La reestructuración del Estado en la dirección de un Estado policial y militar. Parece ahora que el Estado policial significa libertad y el Estado social, esclavitud. Se le quitan al Estado las funciones de la política de desarrollo y de la política referente a la infraestructura económica y social. De esto se deriva la privatización de las propiedades públicas, que resulta en una nueva acumulación originaria. Aparece en el mundo entero un pillaje de estas propiedades.

c) La flexibilización de la fuerza de trabajo, la cual trae consigo la anulación de derechos de importancia decisiva, producto del contrato de trabajo, como la protección frente al despido, el seguro social y la protección de la mujer, pero también de los niños, etc. Las seguridades sociales son disueltas y los sindicatos, debilitados y, muchas veces, también disueltos.

La imposición de estas medidas de ajuste estructural es acompañada en los países claves de América Latina (Brasil, Chile, Argentina) por el terrorismo del Estado, del totalitarismo de la Seguridad Nacional. Este terrorismo mantiene hoy una importancia clave dentro de la estrategia de globalización, como hoy ocurre todavía en Colombia.

La imposición de los ajustes estructurales va de la mano con la propagación de la ideología de la competitividad y de la eficiencia. Por eso, se les justifica como una política de la eliminación de las distorsiones del mercado, o de la eliminación de los "interruptores" de la movilidad de éste. La economía se conduce ahora en términos de una guerra económica, en la cual se trata de conseguir ventajas competitivas que hagan posible salir victorioso de la guerra. La situación misma de los países es discutida en términos de su competitividad, y toda actividad social es evaluada según su aporte a esta competitividad. El economista y, sobre todo, el administrador de empresas, se convierten en asesores militares de esta guerra económica. Su función no es hacer teoría o entender qué significa esta manera de enfocar la 
economía, sino aportar para ganar la guerra. Por eso, la teoría económica y social se torna cínica.

Para esta guerra económica, las medidas de ajuste estructural sirven para preparar y limpiar el campo de batalla. Las empresas que se enfrentan en la guerra económica tienen en común el interés de limpiar el campo de batalla, para poder luchar en él una contra otra sin ser "distorsionadas".

Desde el punto de vista que nos interesa, esta eliminación de las distorsiones del mercado tiene una importancia central. La lógica real del proceso de globalización, se expresa más nítidamente en términos de la eliminación de las distorsiones del mercado. Hace presente este proceso arrollador del mercado total como un inmenso engranaje que sigue una lógica propia y la impone. Por medio de esta lógica, el mercado, como tal engranaje, se autorreproduce, "perfeccionándose" en términos de su propio funcionamiento. Por esta razón, el concepto de las distorsiones del mercado es tan central para el lenguaje. El engranaje del mercado aparece como una gran máquina computacional que necesita ser perfeccionada. Las llamadas distorsiones son consideradas elementos de fricción para este funcionamiento. Sin embargo, una máquina tiene que funcionar con un mínimo de fricciones. Eliminarlas significa mejorar su desempeño. Y se lo mejora eliminando las distorsiones.

La empresa de producción mundial empuja el proyecto y puede imponerlo en el grado que logra el apoyo de los Estados para su realización. No se trata de un proyecto de totalización de algún mercado ideal. El proyecto, entonces, parecería completamente incoherente. Es, más bien, un proyecto de fluidez de los mercados, como el ambiente en el cual actúan las empresas mundiales. Como tal, es coherente. Su realización lo hace presente en forma de una lucha en contra de las "distorsiones" o los "interruptores" del mercado. Todo lo que se interponga a la fluidez de los mercados es visto como distorsión.

De esta manera, lo que desde los años 90 se llama el proyecto de globalización, logra su coherencia. Las funciones del Estado como organizador del desarrollo, su función de garantizar una infraestructura social, y su función de promover un sistema educacional de referencia universal, aparecen ahora como distorsiones del mercado, así como toda defensa del nivel de vida de la población. Las organizaciones

\section{9}

El socavamiento de los derechos humanos en la globalización actual 
populares, inclusive los sindicatos, son percibidos de la misma forma. El Estado como tal, de ningún modo es visto como distorsión del mercado. Lo es únicamente en cuanto Estado con funciones de desarrollo económico y social. Para el proyecto de globalización, su función de promover este proyecto es decisiva. Por consiguiente, el desmantelamiento del Estado, del que se habla tanto, es una reestructuración estatal en función de la promoción del proyecto de globalización, e inclusive, de subvención financiera de su empuje. Pero ahora se trata de subvenciones de cantidades inauditas hacia las empresas mundiales, a las cuales normalmente se les da el nombre de "incentivos". De este Estado se habla como "Estado mínimo", aunque sea un Estado máximo.

A esta luz, las políticas intervencionistas anteriores aparecen como distorsiones del mercado. Por tanto, se habla de antiintervencionismo. Sin embargo, aparece un Estado transformado, que es altamente intervencionista en las relaciones humanas y en las relaciones con la naturaleza. Para no intervenir en los mercados, tiene que intervenir en todas las relaciones sociales en nombre de la privatización y de la flexibilización. No se debe olvidar que la privatización es una política de los poderes públicos. Ellos la hacen, y no los privados. Los intereses privados solamente pueden empujar políticas de privatización de parte de los poderes públicos.

Sin embargo, esta política transforma a las empresas transnacionales - de producción mundial- en poderes por encima de los poderes públicos. Pero son los poderes públicos los que las erigen como sus señores. Con eso, las empresas juntas con los poderes públicos eliminan los derechos humanos de la vida humana de sus respectivas agendas. Pero no son las empresas las que se imponen. No se pueden imponer. Son los poderes públicos los que imponen las empresas y su lógica a la vida humana y a los poderes públicos mismos.

Eso establece el poder de las burocracias privadas por encima de las burocracias públicas, que ahora se transformaron en el apéndice de una dominación absoluta hecha presente en estas burocracias privadas.

\section{El estancamiento dinámico}

El efecto de los ajustes estructurales es la imposibilidad casi completa, por parte de los países dependientes, de promover un desarrollo 
económico autoconcentrado. No pueden promover nuevos centros de actividad moderna, porque los ajustes estructurales excluyen las medidas necesarias para hacerlo. La protección de industrias, el control de divisas, incluso la promoción financiera en favor de empresas nacionales en su competencia con empresas extranjeras ya constituidas, toda política de desarrollo local, nacional y regional quedan relegadas. Aunque el conjunto de empresas del sector moderno tenga mucho dinamismo interno, este dinamismo no es expansivo hacia nuevas regiones, ni con relación al empleo de una nueva fuerza de trabajo.

Aparece el estancamiento dinámico, que también se ha llamado "crecimiento sin nuevos puestos de trabajo" (jobless growth). Alrededor del sector moderno de la economía, se extienden cada vez más los sectores informales y precarios sin ninguna perspectiva a largo plazo. Los sectores modernos se transforman en archipiélagos en un mar de precariedad. Si aparece un aumento del empleo, aparece en estos sectores, y no en los sectores modernos.

Las excepcionse solamente se dan donde los países en desarrollo no se someten indiscriminadamente a los ajustes estructurales, lo que ocurrió especialmente en Asia Oriental. Aparecieron países sumamente dinámicos (los "tigres"), que efectivamente, lograron promover sus propios centros de desarrollo moderno y empresas transnacionales con capacidad competitiva. Sin embargo, con la crisis asiática de 1997, su capacidad de desarrollo autónomo se vio restringida, sobre todo, en el caso de Corea del Sur.

4. Las burocracias privadas toman el poder en nombre de la democracia y los derechos humanos

La estrategia de la globalización — realizada a través de los ajustes estructurales - ha borrado los derechos humanos de la vida humana. Los ajustes estructurales dejan sin efecto los logros anteriores en materia de estos derechos humanos — derechos de la vida, salud, educación, alimentación, vivienda-, y hace imposible volver a recuperarlos. Los ha sustituido por la absolutización de los derechos de las empresas - derechos de propiedad privada- como únicos derechos reconocidos.

Se trata, ahora, sobre todo, de derechos de las grandes burocracias privadas que, en el proceso de globalización, se han impuesto a las

El socavamiento de los derechos humanos en la globalización actual 
burocracias públicas. Estos derechos son presentados como los únicos derechos humanos válidos. Derrotada la burocracia pública, la burocracia privada asumió el poder en nombre de los derechos humanos, reducidos al derecho de propiedad privada. Inclusive, sostiene que no es burocracia, sino "iniciativa privada" en lucha contra la burocracia. La burocracia pública se transformó en el gran promotor del poder de las burocracias privadas. Los principales promotores de la privatización son hoy el Fondo Monetario Internacional (FMI) y el Banco Mundial (BM), que son entidades multinacionales de la burocracia pública. El proyecto del AMI (Acuerdo Multinacional de Inversiones) intenta transformar esta situación de hecho en legalidad constitucional.

En esta situación, es marginado el estatus fundacional del ciudadano. Solamente la burocracia pública tiene ciudadanos. La burocracia privada tiene nada más que clientes. Los tiene en todo el mundo, pero con aquellos que no son clientes, no tiene nada que ver. Se puede tener clientes mundialmente, pero no hay ciudadanos del mundo. La actual exclusión de la población es el resultado de la imposición de las burocracias privadas sobre la burocracia pública. La ciudadanía pierde su significado. Sin embargo, los derechos humanos del ser humano específico - sus derechos emancipatorios - fueron declarados a partir de la ciudadanía. Por tanto, pierden su vigencia.

Max Weber vio esta transformación de la empresa privada en burocracia privada. Habla de "las organizaciones capitalistas privadas, organizadas de una manera cada vez más burocrática" (Weber, Max: Economia y sociedad, pp. 741-742). Sin embargo, siendo coherente con la situación de su tiempo, ve el peligro en la imposición de la burocracia pública. Sobre los sometidos a la burocracia pública generalizada, dice:

Pero si son, en cambio, menos libres, porque toda lucha por el poder con una burocracia estatal es inútil, y porque no se puede apelar alli a instancia alguna interesada en principio contra ella y su poder, como es posible, en cambio, frente a la economía privada. Esta sería toda la diferencia. (Op. cit., pp. 1073-1074)

Una vez eliminado el capitalismo privado, la burocracia estatal dominaria ella sola. Las burocracias privada y pública, que abora trabajan una al lado de la otra y, por lo menos, posiblemente, una contra la otra, manteniéndose, pues, hasta cierto punto, mutuamente en jaque, se fundirian en una jerarquia única, a la manera, por ejemplo del 
Egipto antiguo, sólo que en forma incomparablemente más racional y, por tanto, menos evitable. (Op. cit., p. 1074)

Se puede entender que Max Weber haya tenido este temor en su tiempo. Pero resultó perfectamente equivocado. Donde la burocracia pública logró imponerse a las burocracias privadas - como ocurrió en el socialismo soviético-, fueron los ciudadanos quienes al fin rompieron con su poder. Pero lo que Weber ni siquiera sospechaba, nos toca hoy. Se trata de la imposición de las burocracias privadas, que se devoran a las burocracias públicas. Con mucho más derecho, podemos decir hoy que la burocracia privada lo que Max Weber decía sobre la burocracia pública, es decir, que desde allí se constituye algo que funciona "a la manera, por ejemplo, del Egipto antiguo, sólo en forma incomparablemente más racional y, por tanto, menos evitable". La burocracia pública no era capaz de constituir un poder mundial; la burocracia privada, en cambio, lo ha logrado.

Weber cree todavía que la competencia controla a la burocracia privada, mientras el peligro residiría en la burocracia pública. Por esta razón, el mismo Weber puede seguir pensando en términos de derechos humanos, identificados con el derecho del propietario. Sigue teniendo en mente un individuo-propietario, portador de estos derechos. Hoy no puede haber mucha duda de que es la competencia irrestricta la que lleva al dominio público de la burocracia privada sobre el mundo entero, haciendo pedazos el poder público.

Hoy esta posibilidad que Weber veía, se desvanece. Los derechos humanos tienen que ser derechos específicos del ser humano, y éstos son derechos de un ser natural, corporal. Solamente los derechos humanos, en este sentido, se pueden enfrentar a la tendencia obvia a la dominación absoluta de la burocracia privada - poderes sin ciudadanos- sobre los seres humanos, una tendencia que nos condena a todos a un viaje de Titanic sin retorno.

\section{La democracia en la estrategia de la globalización: El gobierno extraparlamentario}

La estrategia de globalización hace, de esta manera, surgir un poder, que está por encima de toda autoridad política. Cuanto más los mercados se totalizan, tanto menos resulta posible una política frente 
a los mercados. Aparecen los poderes del mercado, que quitan a la política su autonomía.

Estos poderes del mercado operan en nombre de la técnica. Toda política económica es, ahora, aparentemente la aplicación de una técnica, que se presenta como la única forma de racionalidad. Frente a ella, la política parece ser un ámbito de la irracionalidad. Pero estos poderes del mercado dominan la esfera del capital y, por tanto, de los medios de comunicación. No admiten ninguna política frente al mercado, sino que imponen el poder del mercado en nombre de la técnica, la eficiencia y la competitividad, que se erigen en las instancias de juicio sobre todos los valores humanos. Como consecuencia, la política mantiene solamente su autonomía en espacios neutrales desde el punto de vista del poder del mercado, y que no interfieren con la determinación de la sociedad entera por el poder del mercado. Por tanto, este poder determinó el marco dentro del cual la política es posible.

De esta manera, aparece algo similar a un gobierno extraparlamentario, que es, efectivamente, un gobierno mundial, que ejerce el poder sin asumir las funciones del gobierno, ni sus responsabilidades. No necesita ninguna legitimación democrática, sino que se legitima por medio del mercado como la instancia superior de toda vida social. Por eso, está por encima de toda mayoría democrática, que deja de ejercer el poder. Las elecciones no pueden determinar nada que está en conflicto con esta pretendida voluntad general del mercado. Las instancias políticas resultan siendo relativizadas.

Este gobierno extraparlamentario mundial tiene en sus manos, por un lado, a los medios de comunicación y, por el otro, al capital. Gobierna mediante su capacidad de condicionar a los gobiernos políticos legítimos. La huelga del capital llegó a tener importancia central en este condicionamiento de toda política. Eso transformó la bolsa en el criterio determinante de los políticos. La huelga del capital -fuga de capital, migración de empresas, etcétera- puede presionar de tal manera a la política, que ésta pierde su capacidad de orientarse según la voluntad de los electores. Eso ocurre en el contexto de una opinión pública, que está bajo la influencia dominante de los medios de comunicación que están en las manos de este mismo gobierno extraparlamentario. 
Este poder del mercado, sin embargo, es un poder anónimo, y no debe entenderse como un complot planificado. Surge de fuerzas compulsivas de los hechos del mercado. Opera mundialmente, sin tener una coordinación central por parte de instancias humanas. Es coordinada por el mercado y las fuerzas compulsivas de los hechos que emanan del mismo.

Como consecuencia, la democracia ha sido socavada. Ni los gobiernos políticos, ni la oposición parlamentaria, pueden imponer límites significativos a este poder extraparlamentario.

Todo ocurre como en la película Jurassic Park. Había muchos dinosaurios bien limitados en su espacio de actuar, y los humanos podían pasearse tranquilamente para observarlos. Para los dinosaurios, se trataba evidentemente de una distorsión de la competencia, a pesar de que esta situación, para los seres humanos, creó el ambiente de seguridad con el resultado que su posibilidad de vivir no era distorsionada. Sin embargo, con el huracán de la globalización cayeron todas estas distorsiones para los dinosaurios. El tiranosaurus rex podía moverse ahora sin ser distorsionado en su libertad, y el velociraptor lo podía asaltar libremente. Por fin eran global players. Pero ahora estaba distorsionada la vida de los seres humanos. Perdieron todas sus defensas. En la película había un helicóptero, en el cual podían fugarse y, por tanto, salvarse. Pero en nuestra realidad no hay tal helicóptero. Tenemos que defendernos en el terreno.

Eso ha implicado un verdadero cataclismo de los derechos humanos. Estos fueron formalizados en el siglo XVIII por las declaraciones de EE.UU. y de la Revolución Francesa, cuyo centro ha sido la declaración de la propiedad privada como derecho humano fundamental. Son derechos humanos pensados a partir del individuo-propietario, que se enfrenta a las burocracias públicas del Estado. Por tanto, con estas declaraciones surgen, a partir de las luchas de emancipación del siglo XIX y del $\mathrm{xx}$, los derechos del ser humano como sujeto corporal $\mathrm{y}$ concreto: el derecho a no ser esclavo y, por tanto, de no verse sometido al trabajo forzado; los derechos de la emancipación obrera y femenina; los derechos de las etnias; los derechos a la liberación de las colonias. Se trata de los derechos de la vida humana, que muchas veces entran en conflicto con los derechos de propiedad privada. En la Declaración de los Derechos Humanos de la ONU de 1948, muchos de estos derechos de la vida humana son afirmados. 
Sin embargo, en el curso de la estrategia de acumulación de capital conocida como globalización, estos derechos de la vida humana son anulados o marginados. Vuelve el derecho de propiedad privada como derecho humano central $y$, muchas veces, único.

Pero no se trata de una simple vuelta a las declaraciones del siglo XVIII, aunque muchas veces parezca así. La situación de la propiedad privada ha cambiado. En el siglo xvili, el sujeto del derecho de la propiedad privada era el individuo-propietario. Sin embargo, éste ha sido sustituido por las grandes burocracias privadas, que ahora reclaman ser los portadores principales de los derechos humanos. El poder absoluto de estas burocracias privadas se sostiene ahora en nombre de derechos humanos, lo que tiene que subvertir, necesariamente, todos los derechos humanos clásicos. Eso lleva al proceso actual de la subversión de las democracias liberales. El poder público se transforma en apéndice del poder de las burocracias privadas, frente al cual ya no hay ninguna instancia de control. La propia democracia liberal pierde su capacidad de control del poder dominante. Hoy, los derechos humanos centrados en la propiedad privada hacen imposible el control del poder que nos domina, porque las burocracias privadas afirman su poder absoluto en nombre de estos derechos humanos. La propiedad privada como derecho humano central destruye la propia democracia liberal.

Hoy, el único control posible de las burocracias privadas pasa por la intervención en los mercados, que la burocracia privada declara ilegítimo en nombre de su comprensión de los derechos humanos.

\section{La cultura de la desesperanza}

Al declarar esta situación como carente de alternativas, la estrategia de acumulación de capital vigente necesita una cultura de la desesperanza para poder afirmar su legitimidad. Esta es la crisis que vivimos. El poder que ha surgido es un poder total, que sostiene hoy que hay un sistema para el cual no hay alternativa.

Si no hay alternativa para la mayoría de los afectados, no hay esperanza. Las organizaciones de clase o revolucionarias, los movimientos de cambio, la orientación hacia una nueva sociedad, surgieron de la cultura de esperanza de los años 50 y 60 . Formularon la esperanza o la manipularon, sin embargo, se basaron en ella. Se afirmaba que sí hay 
alternativas. La destrucción casi general de los movimientos populares y del Estado de reformas (intervencionista) acabaron con esta cultura, logrando una gran fuerza de convicción a partir de la crisis del socialismo en Europa Oriental. La cultura de la desesperanza se basa en la tesis de que no hay alternativa.

Eso no vale solamente para el proceso de "producción de sobrantes" en el Tercer Mundo. Un proceso parecido se lleva a cabo en el Primer Mundo, aunque a niveles más limitados. En el fondo, la guerra psicológica que, por lo menos en el Tercer Mundo, es omnipresente, trata de convencer a los seres humanos hechos superfluos de que, efectivamente, lo son - con la consecuencia de destruirse mutuamente en vez de ser solidarios entre ellos-. Creo que el primer autor que describió con plena conciencia este mecanismo ha sido Nietzsche. Es sorprendente ver hasta qué grado sabía que el hombre hecho superfluo tiene que considerarse como tal para que se destruya a sí mismo - uno al otro-. Eso es condición de la estabilidad de la sociedad sin esperanza.

Las rebeliones se transforman en movimientos espontáneos, que, al fin, no tienen capacidad de cambio. El caracazo, en febrero de 1989, fue la primera de estas rebeliones sin destino, que terminó en una masacre de miles por la mano militar. Miles de muertos no conmueven y ni siquiera hacen noticia. Las actuales rebeliones en Argentina tienen un carácter parecido. El sistema no se conmueve. Solamente algunas caras de políticos cambian. Todo es más de lo mismo.

Aparecen los crímenes como resultado de la desesperanza. Desde fines de los años 70 -cuando la estrategia de globalización se impone por los ajustes estructurales- empieza la serie de asesinatos-suicidios, que han marcado las décadas siguientes hasta hoy. Empiezan en EE.UU. con los asesinatos-suicidios en colegios, oficinas, en la calle.Se prolongan rápidamente, y aparecen en Europa, en Japón, en Palestina, en África, en China y en el resto de Asia. Su culminación hasta ahora ha sido el atentado suicida del año pasado en Nueva York.

\section{Resurgimiento de la esperanza}

Pero no todo es desesperanza. Aparecen cada vez más movimientos contestatarios. Estos movimientos vienen en nombre de la idea de que un mejor mundo es posible. Se coordinan entre sí, sin intentar 
formar un gran movimiento unificado. Estos movimientos tampoco forman partidos políticos, aunque varios partidos los apoyan. Llegan a ser conocidos con grandes manifestaciones en ocasión de las reuniones de los organismos financieros internacionales. Se hacen presentes durante los últimos años en Seattle, Davos, Praga, Génova y Quebec. En 2001, se reúnen la primera vez a escala mundial en la ciudad brasileña de Porto Alegre, donde organizan un congreso con decenas de participantes. Un congreso parecido se reunión a fines de enero de 2002 en el mismo lugar, donde esta vez hubo más de 50,000 participantes de todo el mundo.

Estos movimientos promueven un pensamiento en términos de alternativas, con una doble orientación: por un lado, para obligar al sistema mundial a reformular toda su estrategia de acumulación de capital llamada estrategia de globalización, y, por el otro, responder a la desesperanza, que cada vez más desemboca en reacciones irracionales sin destino.

Se trata de un movimiento cuyos participantes vienen de todos los sectores de la población. En este sentido, no es un movimiento clasista. En sentido literal, no es un movimiento antiglobalización, sino un movimiento que enfrenta a la actual acumulación mundial de capital. Lo hace, precisamente, en nombre del hecho de que hoy el mundo es efectivamente un mundo global, al que hace falta defenderlo frente a esta estrategia - que se autoproclama globalización-, y que se ha convertido en la peor amenaza para la sostenibilidad de la humanidad y de nuestra tierra hasta ahora. Es un movimiento de la tierra hecha global de los "globalizadores" provenientes de las burocracias privadas y apoyadas por gobiernos que se sienten responsables ante el capital, en vez de ser responsables frente a la gente y a todo nuestro mundo. La "globalización" resulta ser más bien un "pillaje" global de toda la tierra.

Frente a este pillaje global, surge un movimiento de recuperación de la globalidad de la humanidad y de la tierra, en contra de una estrategia de acumulación de capital, que ha asumido ilegítimamente el nombre de "globalización". En vez de globalizar el mundo, lo destruye globalmente.

Este movimiento está en auge y ha adquirido una gran legitimidad en la opinión mundial, hasta en muchos representantes de las propias clases altas. Está presente en todos los países y en todos los sectores 
de la población. Está haciendo conciencia de las consecuencias fatales que la actual estrategia vigente tiene sobre todo el futuro de la humanidad. Se está transformando en el núcleo de una conciencia alternativa: un mejor mundo es posible. Hace ver que la misma globalidad de la tierra exige una alternativa. Mientras, a escala mundial, en muchos la desesperanza lleva a al desesperación con sus consecuencias racionales y sin sentido, aparece una gran recuperación de la esperanza, que también mundialmente se hace notar y que muestra una salida.

\section{La crisis del poder de las burocracias privadas}

Las burocracias privadas de las empresas transnacionales impusieron a todo el mundo una estrategia de acumulación de capital, que lo destruye globalmente. Hoy, después de décadas de imposición, aparecen las reacciones. Como muestran los atentados de Nueva York, estas reacciones pueden ser tan nefastas como lo es la estrategia del poder misma.

Eso lleva a la crisis del poder. Esta crisis no es de por sí una crisis terminal. Tiene hoy todavía el carácter de una encrucijada. Por un lado, es posible reconsiderar toda la estrategia de acumulación de capital llamada globalización, en función de la responsabilidad por una humanidad y una tierra que llegaron a ser globales y que tienen que ser respetadas globalmente para que nuestra vida en el futuro sea posible. Pero, por otro lado, el poder puede caer en la ilusión de poder salvarse por la imposición bruta de su estrategia, contra viento y marea.

En este segundo caso, tiene que imponer un sistema de apoyo diferente del que ha regido hasta ahora. Impuso el mercado total. Para sostenerlo un tiempo más, tiene que complementarlo por un sistema político totalitario y mundial, para callar todas las respuestas posibles. No hay duda que en este momento se está promoviendo eso. En nombre de la guerra antiterrorista aparece la tendencia hacia este sistema totalitario mundial, que pretende algo como un "pinochetismo" mundial. Toda la lucha del poder va en esta dirección. Es el proyecto de los que Stiglitz llama los "fundamentalistas del mercado". Se trata de los “talibán" de la Casa Blanca.

Estamos hoy frente al peligro de la constitución de un poder político total, complementario al poder de las burocracias privadas en el

El socavamiento de los derechos humanos en la globalización actual 
mercado total. Es muy difícil concebir un impedimento. Eso, por e hecho de que no hay en el mundo un poder que se podría enfrentar con medios del poder a este intento. Sin embargo, no es probable que pueda tener éxito. Puede destruir países y matar poblaciones, y parece que lo va a hacer. Pero difícilmente podrá evitar un desmoronamiento interno por las reacciones irracionales que provoca. La rebelión de Argentina resultó en una erupción sin orientación ni estrategia, mientras los atentados a las torres de Nueva York son simplemente reacciones irracionales. Pero, precisamente por eso, no es posible prevenirlos. La guerra antiterrorista es una simple ilusión, y las rebeliones espontáneas sin proyecto no tienen conductores a los que se podría reprimir de antemano. Por eso, si el sistema sigue insistiendo en la imposición ciega de su poder en la línea de su estrategia asumida, provocará solamente un período de decadencia, del cual no podemos saber cuánto durará y qué desastres provocará.

Frente a eso se define el movimiento de oposición a esta estrategia de acumulación del capital. No puede luchar ni con fusiles, ni por medio de algún terror. Puede solamente subvertir la legitimidad del sistema en grupos más amplios y preparar alternativas para el momento en el cual este sistema se hace insostenible frente a las consecuencias desastrosas que está produciendo.

Eso es nuestra tarea en el mundo de hoy. 